\title{
Role of DNA Methylation in the Development and Differentiation of Intestinal Epithelial Cells and Smooth Muscle Cells
}

\author{
Brian G Jorgensen and Seungil Ro* \\ Department of Physiology and Cell Biology, University of Nevada, Reno School of Medicine, Reno, USA
}

The mammalian intestine contains many different cell types but is comprised of 2 main cell types: epithelial cells and smooth muscle cells. Recent in vivo and in vitro evidence has revealed that various alterations to the DNA methylation apparatus within both of these cell types can result in a variety of cellular phenotypes including modified differentiation status, apoptosis, and uncontrolled growth. Methyl groups added to cytosines in regulatory genomic regions typically act to repress associated gene transcription. Aberrant DNA methylation patterns are often found in cells with abnormal growth/differentiation patterns, including those cells involved in burdensome intestinal pathologies including inflammatory bowel diseases and intestinal pseudo-obstructions. The altered methylation patterns being observed in various cell cultures and DNA methyltransferase knockout models indicate an influential connection between DNA methylation and gastrointestinal cells' development and their response to environmental signaling. As these modified DNA methylation levels are found in a number of pathological gastrointestinal conditions, further investigations into uncovering the causative nature, and controlled regulation, of this epigenetic modification is of great interest.

(J Neurogastroenterol Motil 2019;25:377-386)

Key Words

Cell differentiation; DNA methylation; Intestinal mucosa; Muscle smooth

\section{Introduction}

The mammalian intestine is a complex organ containing of a diverse array of cells that have their genesis in all 3 germ layers ${ }^{1}$ and demand careful coordination between each unique cell type in order to accomplish the absorption of dietary nutrients and water, expulsion of waste through peristaltic contractions, as well as provide a physical barrier to pathogens. ${ }^{2}$ The 2 most prominent cellular populations of the intestine are the epithelial and smooth muscle populations. Epithelial cells begin their development as Wnt responsive Lgr $5^{+}$stem cells at the base of intestinal crypts ${ }^{3}$ and differentiate into mature, absorptive Alpi ${ }^{+}, \mathrm{Lgr}^{-}{ }^{-}$enterocytes $(\mathrm{ME})^{4}$ as they move up the villus until they arrive at the villus tip where they undergo apoptosis and extrude themselves into the lumen while the protective barrier is maintained under physiological conditions. ${ }^{5-7}$ These epithelial cells have an incredibly fast turnover rate of 2 to 5 days. ${ }^{1,8}$ Due to the rapid turnover and differentiation observed in intestinal epithelial cells, they have become prime targets for the study of differential expression based on changes in modulable epi-

Received: April 8, 2019 Revised: None Accepted: May 27, 2019

@ This is an Open Access article distributed under the terms of the Creative Commons Attribution Non-Commercial License (http://creativecommons. org/licenses/by-nc/4.0) which permits unrestricted non-commercial use, distribution, and reproduction in any medium, provided the original work is properly cited.

*Correspondence: Seungil Ro, PhD Department of Physiology and Cell Biology, University of Nevada, Reno School of Medicine, MS 0352,1664 N Virginia St. Reno, NV 89557, USA

Tel: +1-775-784-1462, Fax: +1-775-784-6903, E-mail: sro@med.unr.edu 
genetic mechanisms, especially DNA methylation, as both global and site-specific changes in DNA methylation levels are hallmarks of differentiating cells. ${ }^{9-13}$ Several recent in vivo studies have indeed found that DNA methylation levels change at various genomic sites during both development and differentiation of intestinal epithelium from Lgr $5^{+}$stem cells into fully mature ME..$^{14-18}$ Many of these changes strongly correlate with DNA methylation levels found in human disease states such as inflammatory bowel diseases, ${ }^{19-22}$ and certain colorectal cancers. ${ }^{23-27}$ Variable and characteristic patterns of genomic DNA methylation that change under various phenotypic conditions are also found in another cell in the gastrointestinal (GI) tract: smooth muscle cells (SMC).

Surrounding the epithelium, and separated by a submucosal region, are 2 perpendicular layers of smooth muscle (circular and longitudinal) that produce peristaltic movement via calcium initiated, actin-myosin contractions ${ }^{28,29}$ when stimulated by neuronal input mediated through the pace making interstitial cells of Cajal. ${ }^{30,31}$ Unlike most terminally differentiated somatic cells, SMC have a unique plasticity in which they are able to transition between a mature, contractile state, and a synthetic, proliferative, more stem celllike state. ${ }^{32,33}$ Of note, a similar type of dedifferentiation plasticity has recently been observed in villus epithelium. ${ }^{4}$ When comparing the 2 states in SMC, mature SMC express high levels of proteins necessary for contractility such as MYH11, ACTA2, and TAGLN and have low rates of proliferation while synthetic SMC have higher rates of proliferation, lower levels of contractile proteins, produce high levels of extracellular matrix ${ }^{33-35}$ and have lowered levels of the necessary microRNAs (miRNAs), miR-143/145. ${ }^{36}$ These synthetic SMC are no longer functionally contractile and proliferate in response to injury and begin to transition to a more differentiated state once the tissue repair has been accomplished. ${ }^{37}$ This plasticity and ability to proliferate is important for tissue repair but does carry with it the potential for SMC to improperly regulate the dynamic differentiation and growth process. Aberrant growth patterns of SMC in the GI tract is associated with burdensome GI diseases such as megacystis-microcolon-intestinal hypoperistalsis syndrome ${ }^{38-40}$ and intestinal pseudo-obstructions. ${ }^{41,42}$ The combination of plasticity and the potential for the dysregulation of growth/differentiation patterns make SMC a strong candidate for phenotypic alteration through epigenetic mechanism manipulation. In this vein, several research teams have been able to manipulate the phenotypic status of SMC through alteration of DNA methylation mechanisms and enzymes, ${ }^{43-48}$ similar to previously mentioned research into DNA methylation dynamics in intestinal epithelium.

Higher levels of genomic cytosine methylation are regularly associated with gene inactivation or silencing, especially when 5 -methylcytosine $(5-\mathrm{mc})$ nucleotides are within promoters. ${ }^{9,13}$ It is well established that the methylation of cytosines occurs through the transfer of a methyl group from $S$-adenosylmethionine to the fifth position of cytosine, creating 5-mc, catalyzed by 1 of 3 DNA methyltransferases: DNMT1, DNMT3A, and DNMT3B. ${ }^{49-51}$ DNMT3A and DNMT3B are known as de novo methyltransferases as they initially catalyze cytosine to $5-\mathrm{mc}^{51-53}$ while DNMT1 is a maintenance methyltransferase that shows a strong preference for hemimethylated $\mathrm{DNA}^{54-56}$ and cooperates with replication fork machinery ${ }^{57,58}$ suggesting a more active role in rapidly dividing cells that already contain their original de novo 5-mc marks. Here, we review the phenotypic consequences of alterations to the DNA methylation machinery in both intestinal epithelium and GI SMC.

\section{DNA Methylation in Intestinal Epithelium -}

\section{Methylation Dynamics in Developing and Differentiating Intestinal Epithelial Cells}

The GI tract begins its development at the gastrulation stage in early embryonic development. When DNA methylation is inhibited at this early developmental stage in zebrafish embryos through use of cytidine analogs (5-azacytidine, 5-aza and 5-aza-2'deoxycytidine, 5-aza-dC), which non-selectively inhibit all DNMT isoforms and induce hypomethylation, gastrulation does not proceed and muscle progenitors do not organize as expected, ${ }^{59}$ indicating the shared importance of DNA methylation for both epithelial (endoderm) and muscle tissue (mesoderm). As it pertains to intestinal epithelium, there are 2 differentiation states of focus in relation to cellular identity: intestinal epithelial stem cells (IESC) and mature ME. IESC are found at the base of intestinal crypts in close contact to supportive Paneth cells, express Lgr5, have the capacity to become any functional intestinal epithelial cell ${ }^{3}$ and also have the potential to be the origin and driving force behind benign and malignant intestinal neoplasias as IESC are Wnt signaling responsive. ${ }^{60-62} \mathrm{In}$ contrast, ME show little to no Lgr5 expression, strong Alpi expression and only show the ability to become proliferative upon selective elimination of $\mathrm{Lgr}^{+}{ }^{+} \mathrm{IESC}^{4}$ As epithelial cells progress from IESC to $\mathrm{ME}$, there is a loss of Wnt signaling response and an equivalent increase in Bmp signaling response ${ }^{63}$ which, through SMAD1/ SMAD4 activation, directly inhibits the transcription of genes necessary for proliferation. ${ }^{64}$ Many of these genes that have differential expression levels between IESC and ME, also have differential levels of methylation in varying genic elements. Approximately 
$14 \%$ of genes that were induced upon differentiation in intestinal epithelial cells, including ME markers Lct and Alpi, showed losses of methylation while stem cell related genes that lose expression upon differentiation, such as Lgr5 and Olfm4, showed increases in methylation with a majority of these methylation changes occurring in introns, for both gene categories. ${ }^{15}$ Additionally, both Lgr5 and Olfm4 have shown high levels of demethylation across their gene bodies in $\mathrm{Lgr} 5^{+}$cells that are not found in ME. ${ }^{65}$ The most common genomic regions of differential methylation between IESC and $\mathrm{ME}$ are introns, ${ }^{14}$ especially the first intron, ${ }^{15}$ where enhancer regions are often found. In fact, changes in methylation levels at enhancer regions in IESC can impact, and be impacted by, the binding of the Wnt responsive transcription factor, TCF4. ${ }^{14}$ Furthermore, in Dnmt1 \& Dnmt3b ablated HCT116 colon cancer cells, 111 up-regulated genes lost methylation in enhancer regions with about $92 \%$ of those enhancers being found in introns, ${ }^{66}$ a pattern that has been observed in other cell types as well. ${ }^{67,68}$ In contrast, increased methylation at 3' $\mathrm{CpG}$ islands correlates with an increase in related gene expression in both IESC and ME. ${ }^{18}$ Taken together, these data indicate that DNA methylation dynamics play a vital role in intestinal epithelial cell development but how these changes in methylation affect the overall expression of any given gene is specific to genomic and genic location.

\section{Cell Specific Knockout of Dnmt Isoforms Result in Developmental Time Point-dependent Phenotypes}

Dnmt3a and Dnmt1 are the most highly expressed Dnmt isoforms in both total intestinal mucosa (Fig. 1) and isolated epithelial cells. ${ }^{15,18}$ Elimination of Dnmt3a allowed for normal epithelial development ${ }^{18}$ while knockout of Dnmt1 altered epithelial differentiation $^{15}$ and improper renewal of stem cell populations/crypt formation. ${ }^{16}$ Dnmt1 knockout results in differing phenotypes depending on whether the knockout occurs during embryonic development or in adulthood. When Dnmt1 was congenitally and cell-specifically knocked out of all intestinal epithelial cells (using VillinCre), progenitor cells severely reduced their proliferative potential, and had reduced methylation levels upstream of the promoters for genes induced by DNA damage (Cdkn1a, Chek2, Atm, and Mlh1) with only $35 \%$ of knockout pups surviving until weaning, ${ }^{16}$ a phenotype that is very similar to congenital knockout of Dnmt1 in smooth muscle. ${ }^{43}$ Surprisingly, when Dnmt 1 is inducibly eliminated in adult mice (using VillinCreER ${ }^{T 2}$ ), proliferative potential expands up the crypt, instead of being reduced, and cells show both genomic hypomethylation and an overall improper expression of differentiation markers that does not result in the premature death seen in embry- onic Dnmt1 knockout mice. ${ }^{15,16}$ However, it was found that when Dnmt3b was also eliminated from the adult intestinal epithelium alongside Dnmt1 knockout, epithelial development and organization halts altogether as cells become apoptotic and proliferative potential is extinguished. ${ }^{17}$ These results suggest that DNMT3B, who's expression is induced upon Dnmt1 knockout, ${ }^{17}$ has the ability to compensate for the maintenance of de novo methylation patterns lost upon Dnmt1 knockout, which has been observed for LINE1 sequences in embryonic stem cells. ${ }^{70}$ These results stress that expression, or lack thereof, of Dnmt isoforms can be a vital lynchpin at various stages of intestinal cell development (Table). Finally, it has also been shown that loss of methylation in adult intestinal epithelium occurs under germ-free conditions and methylation levels can be rescued upon fecal transplant, ${ }^{18}$ indicating an important developmental crosstalk between the microbiota and intestinal epithelia that requires further investigation.

\section{DNA Methylation Dynamics in Inflammatory Bowel Disease}

Inflammatory bowel disease (IBD) encompasses 2 related but different pathologies affecting the intestinal epithelium that both manifest in pro-inflammatory conditions: Crohn's disease (CD) and ulcerative colitis (UC). In general, both IBD conditions arise in genetically susceptible individuals whose GI mucosa fails to maintain barrier integrity allowing for infiltration of microbiota and other environmental factors that initiate the recruitment of immune cells to the affected area causing the phenotypic inflammatory condition. ${ }^{80} \mathrm{UC}$ is restricted to the colon while $\mathrm{CD}$ can occur anywhere along the GI tract. As both IBD diseases are of unknown etiology, most researchers in the field have turned their attention to establishing genetic, epigenetic, and environmental links to the disease states themselves through forward screening techniques. ${ }^{22,81-83}$ Both diseases states have commonalities in regards to symptom manifestation and genetic loci that are most often associated with immune regulation $^{83,84}$ as well as a the dysbiosis of the gut microbiota. ${ }^{85}$ Many of the genes found to be commonly dysregulated, with correlating aberrant methylation patterns, in the genetics screens of UC affected tissue are associated with regulating apoptosis (Cdkn2a, ${ }^{86,87}$ Dapk, ${ }^{88,89}$ and $C d h 1^{90}$ ) and, in general, UC tissue shows overall genomic hypermethylation. ${ }^{91}$ Even though the number of genetic loci associated with IBD is now over 200, up from 163, these loci only seem to contribute to $13.1 \%$ of the variance seen in CD patients and $8.2 \%$ in UC patients. ${ }^{92,93}$ Thus, as genetic screens are not enough to explain the etiology of these conditions alone, it stands to reason that epigenetics plays some factor as epigenetic mechanisms 
A
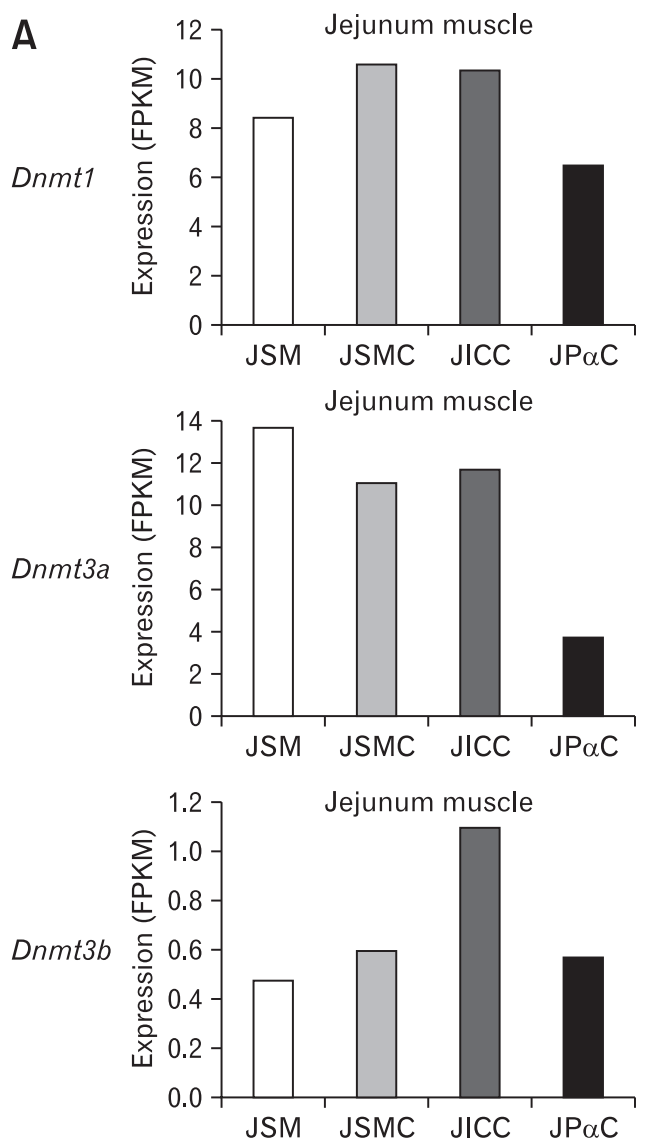

B

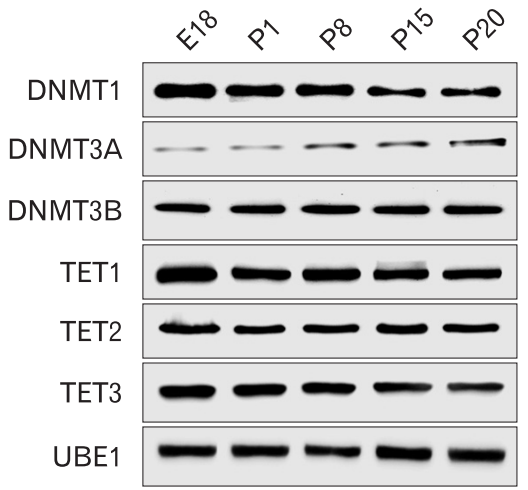

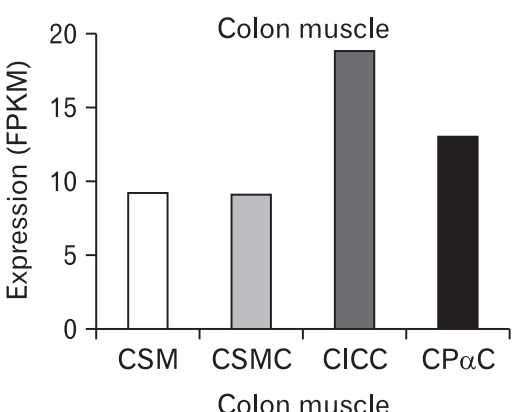
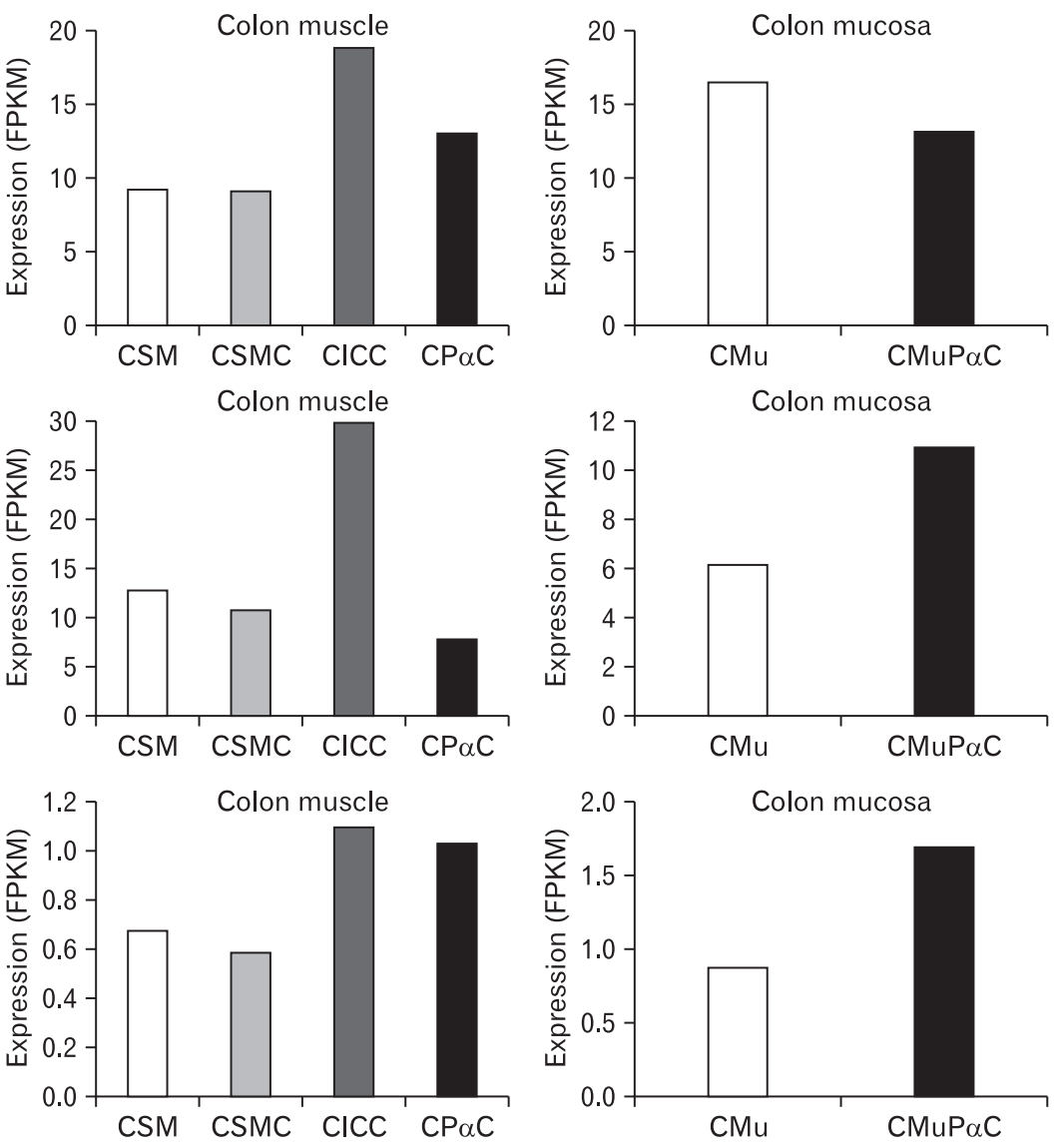

C

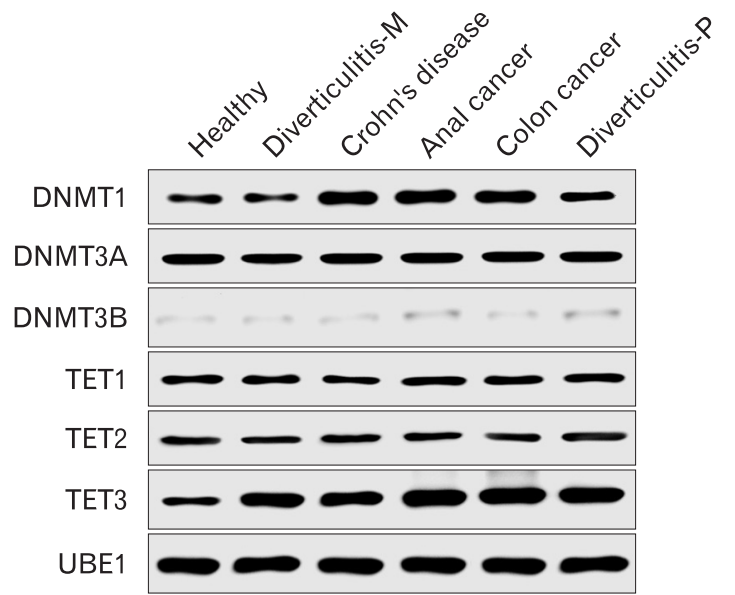

Figure 1. DNA methyltransferase (DNMT) expression levels in intestinal tissue from mice and humans. (A) Using the Smooth Muscle Transcriptome Browser, ${ }^{69}$ we show the expression levels of various DNMTs in several intestinal cell types and tissues (J, jejunal; C, colonic; $\mathrm{SM}$, smooth muscle tissue; SMC, smooth muscle cell; ICC, interstitial cells of Cajal; $\mathrm{P} \alpha \mathrm{C}$, platelet-derived growth factor receptor $\alpha$-positive $\left[\mathrm{PDGFR}^{+}\right]$cell; $\mathrm{Mu}$, mucosa tissue; and $\mathrm{MuP \alpha C}$, mucosal PDGFR $\alpha^{+}$cell). Dnmt3a is the most highly expressed Dnmt isoform in colonic and jejunal smooth muscle tissue but this pattern is not consistent amongst all isolated cell types as $\mathrm{JP} \alpha \mathrm{C} / \mathrm{CP} \alpha \mathrm{C} / \mathrm{CMu} / \mathrm{CMuP} \alpha \mathrm{C}$ express Dnmt 1 more than Dnmt3a with Dnmt3b consistently being expressed the least amongst all cell types and tissues. While these expression levels are informative, they do not indicate necessity as Dnmt1 knockout causes the most detrimental phenotype in both intestinal epithelia and smooth muscle. (B) Expression levels of DNMT and 10-11 traslocation (TET) proteins in mice reveal that DNMT1 reduces its expression over time with a opposite pattern for DNMT3A (Adapted from Jorgensen et $\mathrm{a}^{\mathrm{l3}}{ }^{4}$ ). (C) Variously diseased human tissue shows a dysregulation of DNMT1 and TET3 while other enzymes remain relatively stable in expression across conditions (Adapted from Jorgensen et $\mathrm{al}^{43}$ ). FPKM, Fragments Per Kilobase Million; UBE, Ubiquitin-activating enzyme; $M$, marginal area; P, pouch. 
Table. Phenotypic Outcomes of DNA Methyltransferase Knockout/Inhibition

\begin{tabular}{|c|c|c|c|c|}
\hline & \multicolumn{2}{|r|}{ In vitro } & \multicolumn{2}{|l|}{ In vivo } \\
\hline & \multicolumn{2}{|c|}{ Phenotype upon inhibition/knockout } & \multicolumn{2}{|c|}{ Phenotype upon inhibition/knockout } \\
\hline & Epithelium & Smooth muscle & Epithelium & Smooth muscle \\
\hline Dnmt1 & $\begin{array}{l}\text { No new organoid } \\
\text { formation, already } \\
\text { established organoids } \\
\text { survive }^{15}\end{array}$ & Crypt buds fail to form ${ }^{15}$ & $\begin{array}{l}\text { Crypt Expansion, }{ }^{15} \text { required for } \\
\text { progenitor cell maintenance, }{ }^{16} \text { lethal } \\
\text { when combined with Dnmt3b-KO }{ }^{17}\end{array}$ & $\begin{array}{l}\text { Loss of GI smooth } \\
\text { muscle, lethal by P } 21^{43}\end{array}$ \\
\hline Dnmt3a & $\begin{array}{l}\text { Slower growth and less } \\
\text { foci formation }^{71}\end{array}$ & None reported & $\begin{array}{l}\text { None } 18 \text {, even when combined with } \\
\text { Dnmt1-KO, }{ }^{17} \text { prevents adenoma for- } \\
\text { mation in } \mathrm{Apc}{ }^{\text {min/+ }} \text { mice }^{72}\end{array}$ & None reported \\
\hline Dnmt3b & $\begin{array}{l}\text { Induces apoptosis in } \\
\text { epithelial carcinomas } \\
\text { but not in normal cells }\end{array}$ & Suppresses expression of $\mathrm{p} 53^{74}$ & $\begin{array}{l}\text { Lethal when combined with Dnmt1- } \\
\mathrm{KO} \text {, prevents adenoma formation in } \\
\mathrm{Apc}^{\mathrm{min} /+} \text { mice }^{75}\end{array}$ & None reported \\
\hline All Dnmts & $\begin{array}{l}\text { Aberrant expression of } \\
\text { ileal genes in colon and } \\
\text { vice versa }^{76}\end{array}$ & $\begin{array}{l}\text { Increase of contractile proteins in } \\
\text { high passage } \mathrm{SMC}^{77} \text { and fibro- } \\
\text { blasts, }{ }^{44} \text { stellate cells unable to } \\
\text { transdifferentiate into myofibro- } \\
\text { blasts }^{78}{ }^{2} \mathrm{SMC} \text { unable to alter dif- } \\
\text { ferentiation }^{46}\end{array}$ & $\begin{array}{l}\text { Prevents adenoma formation in } \\
\mathrm{Apc}^{\mathrm{min} /+} \text { mice }^{79}\end{array}$ & None reported \\
\hline
\end{tabular}

DNMT, DNA Methyltransferase; SMC, smooth muscle cells; aSMC, airway SMC; KO, knockout; GI, gastrointestinal.

are the lynchpin between genetics and environment. In 2013, authors Low, Mizoguchi and Mizoguchi produced a comprehensive and in-depth review on the intersection of DNA methylation and IBD, ${ }^{94}$ and as such, we will focus on research published since their publication, henceforth. As there are a myriad of cell types/tissues involved in the pathogenesis of IBD, studies involving DNA methylation changes are not restricted to a single cell type. Studies today tend to focus their attention on mucosal biopsies ${ }^{22,95}$ and blood samples, ${ }^{96}$ specifically immune cells, as both tissues are intricately linked to IBD. DNA methylation profiling of peripheral blood mononuclear cells show that $45 \%$ of differentially methylated positions found in CD samples were also found in UC samples, and 97\% of differentially methylated positions in UC samples were also found in $\mathrm{CD}$ samples highlighting both the similarities and differences of the 2 conditions as it pertains to genomic methylation. ${ }^{96}$ Additionally, levels of $\mathrm{CpG}$ methylation at individual loci, such as TIFAB, are dynamic based on the age of the patient with younger UC patients showing hypomethylation and older patients showing hypermethylation, ${ }^{96}$ again highlighting the situationally dependent modulability of DNA methylation under IBD conditions. Recently, an intricately well-designed and seminal study showed, through the isolation of ileal and colonic intestinal epithelial cells from pediatric patients with IBD, that disease outcome could be predicted utilizing a unique machine learning approach that combines transcrip- tomics and methylomics. ${ }^{22}$ The multi-omics approach of this study is an encouraging diagnostic approach that is much more likely to give a personalized approach to this multi-faceted and individuallydependent disease state that may be transferable to disease states of SMC origin found in the GI tract.

\section{DNA Methylation in Smooth Muscle}

Much of the initial focus that has been given to DNA methylation in SMC has been centered on vascular (vSMC) or airway SMC (aSMC) as these cell types are associated with common, and costly, chronic conditions such as atherosclerosis and asthma, respectively. SMC have an uncommon ability, known as plasticity, to shift between a mature, contractile state and a more proliferative, synthetic condition that is dynamic based on environmental and genetic conditions. ${ }^{33}$ The more proliferative SMC state is phenotypically similar to that of the less-differentiated myofibroblasts through the production of extracellular matrix. ${ }^{37}$ This shift between states of differentiation has repeatedly been shown to be inextricably linked to, and often regulated by, changes in DNA methylation at various genomic elements. ${ }^{13,97,98}$ Early studies on cells at various developmental stages of SMC differentiation (fibroblasts, myofibroblasts, and SMC), made use of cytidine analogs (5-aza and 5-aza-dC) to inhibit DNMT activity under in vitro conditions. ${ }^{446}$ Regardless 
of differentiation status, cytidine analogs consistently interfered with proper differentiation. Hepatic stellate cells were not able to transdifferentiate into myofibroblasts when exposed to 5 -aza-dC. ${ }^{78}$ Cultured aSMC were not able to alter their phenotypic status when subjected to 5 -aza-dC treatment even when the cells were induced to phenotypically switch by the addition of PDGF. ${ }^{46}$ Phenotypic switching in $\mathrm{VSMC}$ was revealed to be regulated by the presence of miR-1298 whose expression is directly dependent on levels of DNA methylation. ${ }^{99}$ In contrast to mature SMC, when cultured fibroblasts were exposed to 5 -aza-dC they began to express higher levels of $\alpha$-SMA, indicating the maturing of fibroblasts towards mature SMC. ${ }^{44}$ Recently, high passage primary human intestinal SMC (iSMC), known for a lack of contractile protein expression compared to lower passage cells, were found to restore their contractile protein expression upon treatment of 5 -aza. ${ }^{77}$ Collectively, these results emphasize the importance of DNA methylation to phenotypic switching in SMC of various origin. Unfortunately, the preponderance of these studies were done in vitro and not on iSMC, and thus, these conclusions needed to be tested in vivo for confirmation across experimental conditions. In order to rectify this, a murine model was employed to show the first in vivo evidence regarding the importance of DNA methylation in the development of iSMC. ${ }^{43}$ In a smooth muscle restricted (Myh11) manner, Dnmt1 was knocked out of the genome resulting in pups with a shortened GI, detrimental thinning of the GI tunica muscularis brought about by the loss of iSMC through apoptosis and significant reductions in mature smooth muscle marker expression. Global genomic methylation of smooth muscle tissue was reduced about $20 \%$ with losses being found in promoters, exons and introns with introns having the largest reductions. These results are in contrast with the previously mentioned iSMC in vitro study ${ }^{77}$ that concludes that inhibition of DNA methylation through 5-aza increases the expression of $\alpha$-SMA and SM22- $\alpha$, both markers of mature SMC.The reconciliation of these diametrically opposed results from in vitro and in vivo iSMC (Table) is vitally important in order to assess the translatability of in vitro results into organisms themselves. A separate group found that when Tet2 was eliminated (a 5-mc deoxygenase that initiates the demethylation of cytosines ${ }^{100,101}$ ) from the murine genome, vSMC do not retain the ability to attenuate necessary SMC growth following arterial injury, ${ }^{45}$ adding further evidence to the notion that regulation of the DNA methylation apparatus is vital to the ordered and highly coordinated processes of growth, development and differentiation in SMC. When considering that a number of GI pathologies find their etiology in the overgrowth of iSMC, and dysregulation of the DNA methylation apparatus in
SMC often creates detrimental growth regulation, it is integral that the next steps in this field be steeped in illuminating the intersection between these interrelated phenomena.

\section{Phenotypic Parallels Between Smooth Mus- cle Cells and Epithelial Cells Resulting From Manipulation of Genomic DNA Methylation Levels}

While SMC and EC diverge in developmental lineages early in the embryo, they share the interdependent physiological goals of GI motility and absorption and thus the fate of one cell type will likely affect the other cell type's homeostasis. Despite epithelial cells being endoderm derived and SMC mesoderm derived, they do share congruous characteristics. As previously mentioned, 5-aza will halt all gastrulation processes that would lead to the development of both mature SMC and epithelial cells in the absence of 5-aza, ${ }^{59}$ indicating both cell types require precise methylation patterns in order to properly develop. Additionally, when Dnmt1 is selectively eliminated from either epithelial cells or SMC, there is little change to any non- $\mathrm{CpG}$ methylation and a majority of the changes at $\mathrm{CpG}$ sites are contained within introns, ${ }^{15,43}$ which can contain regulatory enhancer regions for transcription factors such as TCF4 in epithelial cells ${ }^{14}$ or $\mathrm{SRF}$ in $\mathrm{SMC}^{43}$ that are necessary for differentiation. These studies reveal that $\mathrm{SMC}$ and epithelial cells both show about $35 \%$ loss of overall genomic CpG methylation when Dnmt1 is selectively eliminated, with specific methylation losses occurring at pro-apoptotic genes, such as $\mathrm{Nr} 4 \mathrm{a} 1$ in SMC and Cdkn1a in epithelial cells, resulting in their increased expression and subsequent cell death. Growth patterns of both normal and neoplastic epithelial cells and SMC can be manipulated by interfering with DNA methylation. When Dnmt1 is eliminated from epithelial cells, proliferative potential expands to cells further up the crypt, genomic $\mathrm{CpG}$ methylation is reduced, and aberrant/apoptotic gene expression occurs, leading to lethality at various post-embryonic developmental stages which is exacerbated when combined with Dnmt3b knockout, ${ }^{15-17}$ a phenotype strikingly similar to that found in SMC selective Dnmt1 knockout. ${ }^{43}$ Furthermore, in neoplasias originating from epithelial cells (adenomas) or SMC (leiomyosarcomas), treatment with 5 -aza has been shown to either reverse, or impede any further, proliferation or growth of these tissues, ${ }^{79,102}$ showing additional evidence of the parallel functional necessity of proper DNA methylation patterns in regulating both epithelial cell and SMC growth. Finally, both SMC and epithelial cells contain specific methylation signatures at various differentiation stages. Upon addition of 5-aza, 


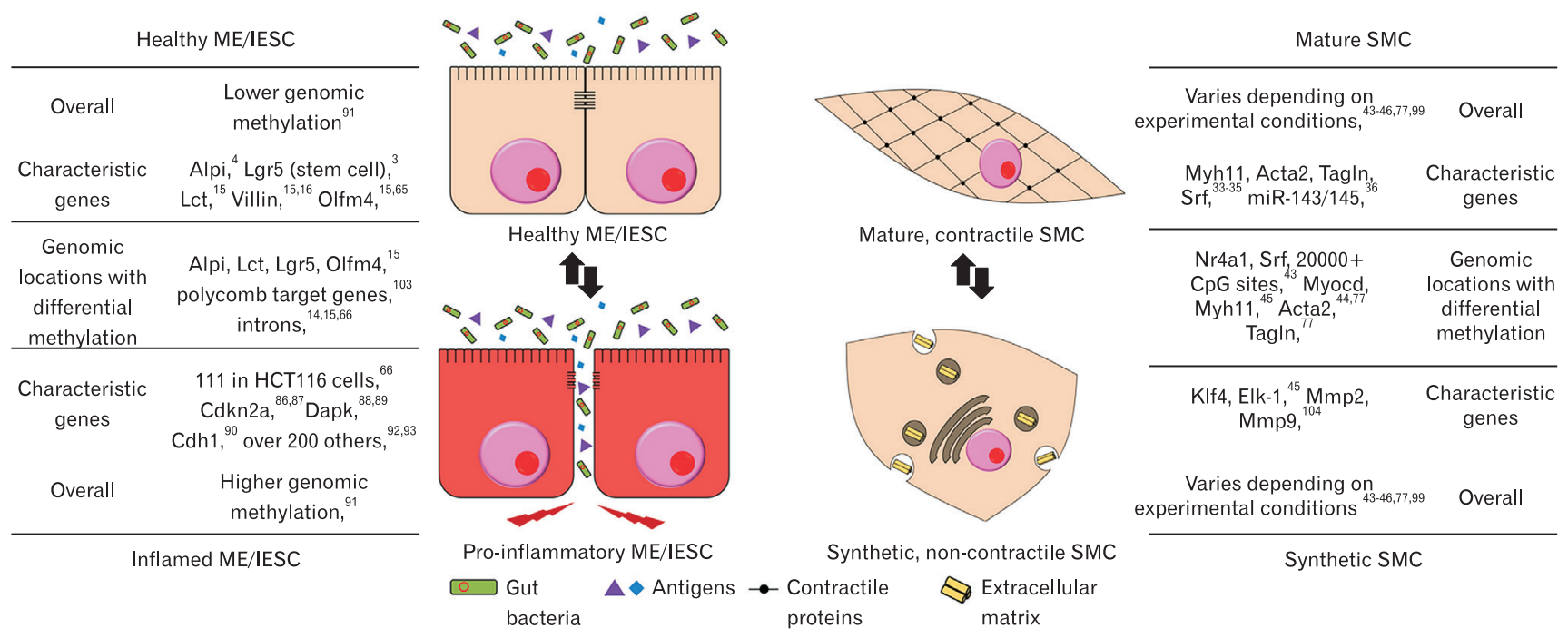

Figure 2. Methylation changes in various stages of intestinal cell phenotype DNA methylation levels are incredibly dynamic during states of pathology and/or differentiation in the gut. Various specific targets and types of genomic location alter their methylation levels, and subsequent expression levels, when these levels change. ME, mature enterocytes; IESC, intestinal epithelial stem cells; SMC, smooth muscle cells.

immature myofibroblasts lose promoter methylation of $\alpha$-SMA, increasing expression, thus beginning the differentiation cascade into mature $\mathrm{SMC}{ }^{44}$ consistent with results from 5-aza addition to high-passage non-contractile SMC that regain strong $\alpha$-SMA expression. ${ }^{77}$ Methylation signatures for epithelial cells can be specific to ileal/colonic location and these $\mathrm{CpG}$ methylation patterns only change in fetal epithelial cells while adult epithelial cells retain consistent methylation signatures, ${ }^{76}$ demonstrating that precise $\mathrm{CpG}$ methylation patterns are necessary for development of epithelial cells from embryonic stages but not necessarily for the proper functioning of adult cells. Further studies on both cultured and in vivo epithelial cells and SMC will elucidate more consequential correlations, and contrasts, that result from changes in DNA methylation.

\section{Conclusion}

The GI tract is a massively complex organ system that, in varying cell types, relies on careful regulation of DNA methylation patterns in order to develop or differentiate as needed. Careful, and conditionally dependent, coordination of DNA methylation patterns and locations is crucial to ensure necessary growth and differentiation as well as when to halt these same processes (Fig. 2). As aberrant DNA methylation patterns, or altered DNMT levels, have been useful in understanding and treating pathologies in the intestinal epithelium, similar strategies should be employed for SMC disease states in the GI tract.
Financial Support: This work was supported by 2 grants from the National Institute of Health (DK094886 and DK103055) awarded to Seungil Ro.

\section{Conflicts of Interest: None.}

Author Contributions: Brian G Jorgensen drafted the original manuscript draft, figures and tables initiated with intellectual directives and contributions from Seungil Ro; and Seungil Ro edited, revised, and completed the manuscript draft.

\section{References}

1. de Santa Barbara P, van den Brink GR, Roberts DJ. Development and differentiation of the intestinal epithelium. Cell Mol Life Sci 2003;60:1322-1332.

2. van der Flier LG, Clevers H. Stem cells, self-renewal, and differentiation in the intestinal epithelium. Annu Rev Physiol 2009;71:241-260.

3. Barker N, van Es JH, Kuipers J, et al. Identification of stem cells in small intestine and colon by marker gene Lgr5. Nature 2007;449:1003-1007.

4. Tetteh PW, Basak O, Farin HF, et al. Replacement of lost Lgr5-positive stem cells through plasticity of their enterocyte-lineage daughters. Cell Stem Cell 2016;18:203-213.

5. Bullen TF, Forrest S, Campbell F, et al. Characterization of epithelial cell shedding from human small intestine. Lab Invest 2006;86:1052-1063.

6. Vereecke L, Beyaert R, van Loo G. Enterocyte death and intestinal barrier maintenance in homeostasis and disease. Trends Mol Med 2011;17:584-593.

7. Watson AJ, Chu S, Sieck L, et al. Epithelial barrier function in 
vivo is sustained despite gaps in epithelial layers. Gastroenterology 2005;129:902-912.

8. Potten CS. Stem cells in gastrointestinal epithelium: numbers, characteristics and death. Philos Trans R Soc B Biol Sci 1998;353:821-830.

9. Borgel J, Guibert S, Li Y, et al. Targets and dynamics of promoter DNA methylation during early mouse development. Nat Genet 2010;42:10931100.

10. Lister R, Pelizzola M, Dowen RH, et al. Human DNA methylomes at base resolution show widespread epigenomic differences. Nature 2009;462:315-322.

11. Farlik M, Halbritter F, Müller F, et al. DNA methylation dynamics of human hematopoietic stem cell differentiation. Cell Stem Cell 2016;19:808-822.

12. Bock C, Beerman I, Lien WH, et al. DNA methylation dynamics during in vivo differentiation of blood and skin stem cells. Mol Cell 2012;47:633-647.

13. Smith ZD, Meissner A. DNA methylation: roles in mammalian development. Nat Rev Genet 2013;14:204-220.

14. Kaaij LT, van de Wetering M, Fang F, et al. DNA methylation dynamics during intestinal stem cell differentiation reveals enhancers driving gene expression in the villus. Genome Biol 2013;14:R50.

15. Sheaffer KL, Kim R, Aoki R, et al. DNA methylation is required for the control of stem cell differentiation in the small intestine. Genes Dev 2014;28:652-664.

16. Elliott EN, Sheaffer KL, Schug J, Stappenbeck TS, Kaestner KH. Dnmt1 is essential to maintain progenitors in the perinatal intestinal epithelium. Development 2015;142:2163-2172.

17. Elliott EN, Sheaffer KL, Kaestner KH. The 'de novo' DNA methyltransferase Dnmt3b compensates the Dnmt1-deficient intestinal epithelium. Elife Publisged Online First: 25 Jan 2016. doi: 10.7554/ eLife. 12975.

18. Yu DH, Gadkari M, Zhou Q, et al. Postnatal epigenetic regulation of intestinal stem cells requires DNA methylation and is guided by the microbiome. Genome Biol 2015;16:211.

19. Saito S, Kato J, Hiraoka S, et al. DNA methylation of colon mucosa in ulcerative colitis patients: correlation with inflammatory status. Inflamm Bowel Dis 2011;17:1955-1965.

20. Lin Z, Hegarty JP, Cappel JA, et al. Identification of disease-associated DNA methylation in intestinal tissues from patients with inflammatory bowel disease. Clin Genet 2011;80:59-67.

21. Karatzas PS, Gazouli M, Safioleas M, Mantzaris GJ. DNA methylation changes in inflammatory bowel disease. Ann Gastroenterol 2014;27:125132.

22. Howell KJ, Kraiczy J, Nayak KM, et al. DNA methylation and transcription patterns in intestinal spithelial cells from pediatric patients with inflammatory bowel diseases differentiate disease subtypes and associate with outcome. Gastroenterology 2018;154:585-598.

23. Sheaffer KL, Elliott EN, Kaestner KH. DNA hypomethylation contributes to genomic instability and intestinal cancer initiation. Cancer Prev Res 2016;9:534-546.

24. Lao VV, Grady WM. Epigenetics and colorectal cancer. Nat Rev Gastroenterol Hepatol 2011;8:686-700.
25. Lam K, Pan K, Linnekamp J, Medema JP, Kandimalla R. DNA methylation based biomarkers in colorectal cancer: a systematic review. Biochim Biophys Acta 2016;1866:106-120.

26. Luo Y, Wong CJ, Kaz AM, et al. Differences in DNA methylation signatures reveal multiple pathways of progression from adenoma to colorectal cancer. Gastroenterology 2014;147:418-429, e8.

27. Toyota M, Ahuja N, Ohe-Toyota M, Herman JG, Baylin SB, Issa PJ. $\mathrm{CpG}$ island methylator phenotype in colorectal cancer. Proc Nayl Acad Sci USA 1999;96:8681-8686.

28. Somlyo AP, Somlyo AV. Signal transduction and regulation in smooth muscle. Nature 1994;372:231-236.

29. Horowitz A, Menice CB, Laporte R, Morgan KG. Mechanisms of smooth muscle contraction. Physiol Rev 1996;76:967-1003.

30. Sanders KM. A case for interstitial cells of Cajal as pacemakers and mediators of neurotransmission in the gastrointestinal tract. Gastroenterology 1996;111:492-515.

31. Sanders KM, Koh SD, Ro S, Ward SM. Regulation of gastrointestinal motility - insights from smooth muscle biology. Nat Rev Gastroenterol Hepatol 2012;9:633-645.

32. Liu R, Leslie KL, Martin KA. Epigenetic regulation of smooth muscle cell plasticity. Biochim Biophys Acta 2015;1849:448-453.

33. Owens GK. Regulation of differentiation of vascular smooth muscle cells. Physiol Rev 1995;75:487-517.

34. Sobue K, Hayashi KI, Nishida W. Expressional regulation of smooth muscle cell-specific genes in association with phenotypic modulation. In: Muscle Physiology and Biochemistry. Springer US: Boston MA 1999:105-118.

35. Rzucidlo EM, Martin KA, Powell RJ. Regulation of vascular smooth muscle cell differentiation. J Vasc Surg 2007;45(suppl A):A25-A32.

36. Cordes KR, Sheehy NT, White MP, et al. miR-145 and miR-143 regulate smooth muscle cell fate and plasticity. Nature 2009;460:705-710.

37. Owens GK, Kumar MS, Wamhoff BR. Molecular regulation of vascular smooth muscle cell differentiation in development and disease. Physiol Rev 2004;84:767-801.

38. Piotrowska AP, Rolle U, Chertin B, De Caluwé D, Bianchi A, Puri P. Alterations in smooth muscle contractile and cytoskeleton proteins and interstitial cells of Cajal in megacystis microcolon intestinal hypoperistalsis syndrome. J Pediatr Surg 2003;38:749-755.

39. Rolle U, O'Briain S, Pearl RH, Puri P. Megacystis-microcolon-intestinal hypoperistalsis syndrome: evidence of intestinal myopathy. Pediatr Surg Int 2002;18:2-5.

40. Wangler MF, Gonzaga-Jauregui C, Gambin T, et al. Heterozygous de novo and inherited mutations in the smooth muscle actin (ACTG2) gene underlie megacystis-microcolon-intestinal hypoperistalsis syndrome. PLoS Genet 2014;10:e1004258.

41. Moore SW, Schneider JW, Kaschula RO. Unusual variations of gastrointestinal smooth muscle abnormalities associated with chronic intestinal pseudo-obstruction. Pediatr Surg Int 2002;18:13-20.

42. Mallick S, Prasenjit D, Prateek K, et al. Chronic intestinal pseudoobstruction: systematic histopathological approach can clinch vital clues. Virchows Arch 2014;464:529-537.

43. Jorgensen BG, Berent RM, Ha SE, et al. DNA methylation, through 
DNMT1, has an essential role in the development of gastrointestinal smooth muscle cells and disease. Cell Death Dis 2018;9:474.

44. Hu B, Gharaee-Kermani M, Wu Z, Phan SH. Epigenetic regulation of myofibroblast differentiation by DNA methylation. Am J Pathol 2010;177:21-28.

45. Liu R, Jin Y, Tang WH, et al. Ten-eleven traslocation-2 (TET2) is a master regulator of smooth muscle cell plasticity. Circulation 2013;128:2047-2057.

46. Ning Y, Huang H, Dong Y, et al. 5-Aza-2'-deoxycytidine inhibited PDGF-induced rat airway smooth muscle cell phenotypic switching. Arch Toxicol 2013;87:871-881.

47. Zhuang J, Luan P, Li H, et al. The yin-yang dynamics of DNA methylation is the key regulator for smooth muscle cell phenotype switch and vascular remodeling. Arterioscler Thromb Vasc Biol 2017;37:84-97.

48. Connelly JJ, Cherepanova OA, Doss JF, et al. Epigenetic regulation of COL15A1 in smooth muscle cell replicative aging and atherosclerosis. Hum Mol Genet 2013;22:5107-5120.

49. Jeltsch A, Jurkowska RZ. DNA methyltransferases-role and function. Switzerland: Springer International Publishing 2016:1-19.

50. Zhang ZM, Liu S, Lin K, et al. Crystal structure of human DNA methyltransferase 1. J Mol Biol 2015;427:2520-2531.

51. Zhang ZM, Lu R, Wang P, et al. Structural basis for DNMT3Amediated de novo DNA methylation. Nature 2018;554:387-391.

52. Okano M, Bell DW, Haber DA, Li E. DNA methyltransferases Dn$\mathrm{mt} 3 \mathrm{a}$ and Dnmt3b are essential for de novo methylation and mammalian development. Cell 1999;99:247-257.

53. Kaneda M, Okano M, Hata K, et al. Essential role for de novo DNA methyltransferase Dnmt3a in paternal and maternal imprinting. Nature 2004;429:900-903.

54. Li E, Bestor TH, Jaenisch R. Targeted mutation of the DNA methyltransferase gene results in embryonic lethality. Cell 1992;69:915-926.

55. Hsieh C-L. The de novo methylation activity of Dnmt3a is distinctly different than that of Dnmt1. BMC Biochem 2005;6:6.

56. Hermann A, Goyal R, Jeltsch A. The Dnmt1 DNA-(cytosine-C5)methyltransferase methylates DNA processively with high preference for hemimethylated target sites. J Biol Chem 2004;279:48350-48359.

57. Liu X, Gao Q, Li P, et al. UHRF1 targets DNMT1 for DNA methylation through cooperative binding of hemi-methylated DNA and methylated H3K9. Nat Commun 2013;4:1563.

58. Hervouet E, Vallette FM, Cartron PF. Dnmt1/transcription factor interactions: an alternative mechanism of DNA methylation inheritance. Genes Cancer 2010;1:434-443.

59. Martin CC, Laforest L, Akimenko MA, Ekker M. A role for DNA methylation in gastrulation and somite patterning. Dev Biol 1999;206:189-205.

60. de Sousa e Melo F, Kurtova AV, Harnoss JM, et al. A distinct role for $\operatorname{Lgr} 5^{+}$stem cells in primary and metastatic colon cancer. Nature 2017;543:676-680.

61. Schepers AG, Snippert HJ, Stange DE, et al. Lineage tracing reveals $\operatorname{Lgr} 5^{+}$stem cell activity in mouse intestinal adenomas. Science 2012;337:730-735.

62. Barker N, Ridgway RA, van Es JH, et al. Crypt stem cells as the cells-of- origin of intestinal cancer. Nature 2009;457:608-611.

63. He XC, Zhang J, Tong WG, et al. BMP signaling inhibits intestinal stem cell self-renewal through suppression of wnt-beta-catenin signaling. Nat Genet 2004;36:1117-1121.

64. Qi Z, Li Y, Zhao B, et al. BMP restricts stemness of intestinal Lgr5 ${ }^{+}$ stem cells by directly suppressing their signature genes. Nat Commun 2017;8:13824.

65. Kim R, Sheaffer KL, Choi I, Won K, Kaestner KH. Epigenetic regulation of intestinal stem cells by Tet1-mediated DNA hydroxymethylation. Genes Dev 2016;30:2433-2442.

66. Blattler A, Yao L, Witt H, et al. Global loss of DNA methylation uncovers intronic enhancers in genes showing expression changes. Genome Biol 2014;15:469.

67. Hoivik EA, Bjanesoy TE, Mai O, et al. DNA methylation of intronic enhancers directs tissue-specific expression of steroidogenic factor $1 / \mathrm{ad}$ renal 4 binding protein (SF-1/Ad4BP). Endocrinology 2011;152:21002112.

68. Anastasiadi D, Esteve-Codina A, Piferrer F. Consistent inverse correlation between DNA methylation of the first intron and gene expression across tissues and species. Epigenetics Chromatin 2018;11:37.

69. Breland A, Ha SE, Jorgensen BG, et al. Smooth muscle transcriptome browser: offering genome-wide references and expression profiles of transcripts expressed in intestinal SMC, ICC, and PDGFR $\alpha^{+}$cells. Sci Rep 2019;9:387.

70. Liang G, Chan MF, Tomigahara Y, et al. Cooperativity between DNA methyltransferases in the maintenance methylation of repetitive elements. Mol Cell Biol 2002;22:480-491.

71. Cui $\mathrm{H}$, Zhao C, Gong $\mathrm{P}$, et al. DNA methyltransferase $3 \mathrm{~A}$ promotes cell proliferation by silencing $\mathrm{CDK}$ inhibitor $\mathrm{p} 18^{\mathrm{INK} 4 \mathrm{C}}$ in gastric carcinogenesis. Sci Rep 2015;5:13781.

72. Weis B, Schmidt J, Maamar H, et al. Inhibition of intestinal tumor formation by deletion of the DNA methyltransferase 3a. Oncogene 2015;34:1822-1830.

73. Beaulieu N, Morin S, Chute IC, Robert MF, Nguyen H, MacLeod AR. An essential role for DNA methyltransferase DNMT3B in cancer cell survival. J Biol Chem 2002;277:28176-28181.

74. Cao C, Zhang H, Zhao L, et al. miR-125b targets DNMT3b and mediates p53 DNA methylation involving in the vascular smooth muscle cells proliferation induced by homocysteine. Exp Cell Res 2016;347:95-104.

75. Lin H, Yamada Y, Nguyen S, et al. Suppression of intestinal neoplasia by deletion of Dnmt3b. Mol Cell Biol 2006;26:2976-2983.

76. Kraiczy J, Nayak KM, Howell KJ, et al. DNA methylation defines regional identity of human intestinal epithelial organoids and undergoes dynamic changes during development. Gut 2019;68:49-61.

77. Bonafiglia QA, Lourenssen SR, Hurlbut DJ, Blennerhassett MG. Epigenetic modification of intestinal smooth muscle cell phenotype during proliferation. Am J Physiol Cell Physiol 2018;315:C722-C733.

78. Mann J, Oakley F, Akiboye F, Elsharkawy A, Thorne AW, Mann DA. Regulation of myofibroblast transdifferentiation by DNA methylation and $\mathrm{MeCP}$ : implications for wound healing and fibrogenesis. Cell Death Differ 2007;14:275-285.

79. Laird PW, Jackson-Grusby L, Fazeli A, et al. Suppression of intestinal 
neoplasia by DNA hypomethylation. Cell 1995;81:197-205.

80. Kaser A, Zeissig S, Blumberg RS. Inflammatory bowel disease. Annu Rev Immunol 2010;28:573-621.

81. Barrett JC, Hansoul S, Nicolae DL, et al. Genome-wide association defines more than 30 distinct susceptibility loci for Crohn's disease. Nat Genet 2008;40:955-962.

82. Anderson CA, Boucher G, Lees CW, et al. Meta-analysis identifies 29 additional ulcerative colitis risk loci, increasing the number of confirmed associations to 47. Nat Genet 2011;43:246-252.

83. Ek WE, Amato MD, Halfvarson J. The history of genetics in inflammatory bowel disease. Ann Gastroenterol 2014;27:294-303.

84. de Lange KM, Moutsianas L, Lee JC, et al. Genome-wide association study implicates immune activation of multiple integrin genes in inflammatory bowel disease. Nat Genet 2017;49:256-261.

85. Nishida A, Inoue R, Inatomi O, Bamba S, Naito Y, Andoh A. Gut microbiota in the pathogenesis of inflammatory bowel disease. Clin J Gastroenterol 2018;11:1-10.

86. Hsieh CJ, Klump B, Holzmann K, Borchard F, Gregor M, Porschen R. Hypermethylation of the p16(INK4a) promoter in colectomy specimens of patients with long-standing and extensive ulcerative colitis. Cancer Res 1998;58:3942-3945.

87. Moriyama T, Matsumoto T, Nakamura S, et al. Hypermethylation of p14(ARF)may be predictive of colitic cancer in patients with ulcerative colitis. Dis Colon Rectum 2007;50:1384-1392.

88. Steinmann S, Scheibe K, Erlenbach-Wuensch K, Neufert C, SchneiderStock R. Death-associated protein kinase: a molecule with functional antagonistic duality and a potential role in inflammatory bowel disease (Review). Int J Oncol 2015;47:5-15.

89. Kuester D, Guenther T, Biesold S, et al. Aberrant methylation of DAPK in long-standing ulcerative colitis and ulcerative colitis-associated carcinoma. Pathol Res Pract 2010;206:616-624.

90. Wheeler JM, Kim HC, Efstathiou JA, Ilyas M, Mortensen NJ, Bodmer WF. Hypermethylation of the promoter region of the E-cadherin gene (CDH1) in sporadic and ulcerative colitis associated colorectal cancer. Gut 2001;48:367-371.

91. Gould NJ, Davidson KL, Nwokolo CU, Arasaradnam RP. A systematic review of the role of DNA methylation on inflammatory genes in ulcerative colitis. Epigenomics 2016;8:667-684.
92. Liu JZ, van Sommeren S, Huang H, et al. Association analyses identify 38 susceptibility loci for inflammatory bowel disease and highlight shared genetic risk across populations. Nat Genet 2015;47:979-986.

93. Jostins L, Ripke S, Weersma RK, et al. Host-microbe interactions have shaped the genetic architecture of inflammatory bowel disease. Nature 2012;491:119-124.

94. Low D, Mizoguchi A, Mizoguchi E. DNA methylation in inflammatory bowel disease and beyond. World J Gastroenterol 2013;19:52385249.

95. Harris RA, Nagy-Szakal D, Mir SA, et al. DNA methylation-associated colonic mucosal immune and defense responses in treatment-naïve pediatric ulcerative colitis. Epigenetics 2014;9:1131-1137.

96. McDermott E, Ryan EJ, Tosetto M, et al. DNA methylation profiling in inflammatory bowel disease provides new insights into disease pathogenesis. J Crohn's Colitis 2016;10:77-86.

97. Jones PA, Taylor SM. Cellular differentiation, cytidine analogs and DNA methylation. Cell 1980;20:85-93.

98. Meissner A, Mikkelsen TS, Gu H, et al. Genome-scale DNA methylation maps of pluripotent and differentiated cells. Nature 2008;454:766770

99. Hu W, Wang M, Yin H, et al. MicroRNA-1298 is regulated by DNA methylation and affects vascular smooth muscle cell function by targeting connexin 43. Cardiovasc Res 2015;107:534-545.

100. Aventín A, La Starza R, Martínez C, et al. Involvement of MLL gene in a t $(10 ; 11)(\mathrm{q} 22 ; \mathrm{q} 23)$ and at $(8 ; 11)(\mathrm{q} 24 ; \mathrm{q} 23)$ identified by fluorescence in situ hybridization. Cancer Genet Cytogenet 1999;108:48-52.

101. Ito S, D’Alessio AC, Taranova OV, Hong K, Sowers LC, Zhang Y. Role of tet proteins in $5 \mathrm{mC}$ to $5 \mathrm{hmC}$ conversion, ES-cell self-renewal and inner cell mass specification. Nature 2010;466:1129-1133.

102. De Carvalho Fischer C, Hu Y, Morreale M, et al. Treatment with epigenetic agents profoundly inhibits tumor growth in leiomyosarcoma. Oncotarget 2018;9:19379-19395.

103. Hahn MA, Hahn T, Lee DH, et al. Methylation of polycomb target genes in intestinal cancer is mediated by inflammation. Cancer Res 2008;68:10280-10289.

104. Ailawadi G, Moehle CW, Pei H, et al. Smooth muscle phenotypic modulation is an early event in aortic aneurysms. J Thorac Cardiovasc Surg 2009;138:1392-1399. 